\title{
EVALUATION OF ALTERNATIVE CONFIGURATIONS OF A WATER-OIL HEAT EXCHANGER SYSTEM
}

\author{
A. L. V. Gonçalves ${ }^{\mathrm{a}}$, \\ and A. S. Francisco ${ }^{b}$ \\ Universidade Federal Fluminense (UFF) \\ Escola de Engenharia Industrial \\ Metalúrgica de Volta Redonda \\ Avenida dos trabalhadores, 420 \\ Bairro Vila Santa Cecília \\ Volta Redonda, RJ, Brasil \\ CEP 27255-125 \\ aalvg.velloso@gmail.com \\ bafrancisco@metal.eeimvr.uff.br \\ Received: April 13, 2016 \\ Revised: July 11, 2016 \\ Accepted: September 12, 2016
}

\section{ABSTRACT}

The success in performance of equipment at industrial facilities is associated with its capacity of normal operation. When some equipment is subject to maintenance at large cost, the operation is uninteresting or even impracticable. The heat exchanger is an equipment widely employed, which performs transfer of heat between two fluids at different temperatures, separated by a solid wall. In this work, we evaluate alternative configurations of a system of shell-and-tube heat exchangers, aiming to improve the performance of this system in economical point of view, and to mitigate the maintenance cost. We use the effectiveness method to obtain outlet temperature values, and compare such results with values measured in situ. We conclude that alternative configurations are feasible in order to improve the thermal performance of the system of heat exchangers, reducing installation cost.

Keywords: heat exchanger, effectiveness method, thermal performance

\section{NOMENCLATURE}

A heat transfer area, $\mathrm{m}^{2}$

$C_{h} \quad$ thermal capacity of the hot fluid, $\mathrm{J} /(\mathrm{kg} . \mathrm{K})$

$C_{c} \quad$ thermal capacity of the cold fluid, $\mathrm{J} /(\mathrm{kg} . \mathrm{K})$

$C_{\text {max }}$ maximum thermal capacity, $\mathrm{J} /(\mathrm{kg} . \mathrm{K})$

$C_{\min }$ minimum thermal capacity, $\mathrm{J} /(\mathrm{kg} . \mathrm{K})$

$N$ number of heat transfer units (NUT)

$Q \quad$ actual heat transfer rate, $\mathrm{J} / \mathrm{s}$

$Q_{\max }$ largest possible heat transfer rate, $\mathrm{J} / \mathrm{s}$

$T_{h, 1} \quad$ inlet temperature of the hot fluid, $\mathrm{K}$

$T_{c, 1} \quad$ inlet temperature of the cold fluid, $\mathrm{K}$

$U \quad$ overall heat transfer coefficient, $\mathrm{W} /\left(\mathrm{m}^{2} . \mathrm{K}\right)$

\section{Greek symbols}
$\beta \quad$ parameter
$\varepsilon \quad$ effectiveness

\section{Subscripts}

$\begin{array}{ll}\mathrm{c} & \text { cold fluid } \\ \mathrm{h} & \text { hot fluid } \\ \max & \text { maximum } \\ \min & \text { minimum } \\ 1 & \text { inlet } \\ 2 & \text { outlet }\end{array}$

\section{INTRODUCTION}

In this work, the effectiveness method is applied for evaluating alternative configurations of a system of heat exchangers, aiming to improve its thermal performance. Since the start of operation, such system is subjected to inlay phenomena, which cause loss of thermal performance of the system (Tonin, 2003).

We suggest four alternative configurations for the system in order to improve the thermal performance of an existing configuration. We apply the effectiveness method to obtain outlet temperatures of the existing configuration. The method is validated by comparisons of its results with data in situ. Next, we obtain the outlet temperatures of the four alternative configurations, applying the validated method.

The implementation of the four alternative configurations has provided improvements in thermal performance of the system. However, just two of the alternative configurations have been economically feasible relative to the installation cost for carrying out the modifications in the system.

\section{THE SYSTEM OF HEAT EXCHANGERS}

In some chemical plant in which is necessary to discard oil at low temperatures, a cooling process is carried out through a system of heat exchangers that takes cooling water from a river. The system consists of a set of ten shell-and-tube heat exchangers, classified as BES type in compliance with the code ASME (2007). 
The oil gets into the system of heat exchangers at temperature about $112^{\circ} \mathrm{C}$ and comes out at temperature about $36^{\circ} \mathrm{C}$. In each heat exchanger, the oil flows in four passes on the tube side, and proceeds to the next heat exchangers in series, as shown in Fig.1. The water flows on the shell side, entering in each pair of heat exchangers in parallel.

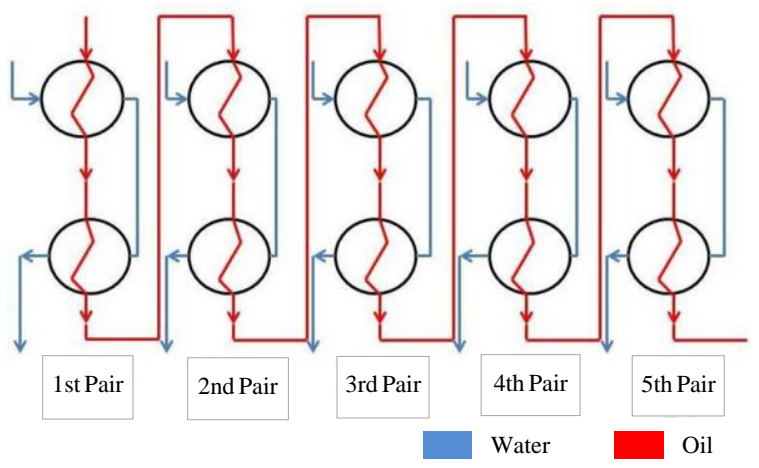

Figure 1. The existing configuration of the system of heat exchangers.

For the existing configuration of the system of heat exchangers, structural and process data are available, such as geometric dimensions of heat exchanger, inlet temperatures, inlet pressures, oil and water properties. Table 1 shows the geometric dimensions of one heat exchanger.

Table 1. Sizes in each heat exchanger.

\begin{tabular}{|l|c|}
\hline \multicolumn{1}{|c|}{ Description } & Value \\
\hline Spacing between tube & $0.006045 \mathrm{~m}$ \\
\hline Tube length & $5.77 \mathrm{~m}$ \\
\hline Length of the tube bundle & $5.77 \mathrm{~m}$ \\
\hline Outside diameter of the shell & $1.275 \mathrm{~m}$ \\
\hline Outside diameter of the tubes & $0.025705 \mathrm{~m}$ \\
\hline Internal diameter of the shell & $1.25 \mathrm{~m}$ \\
\hline Internal diameter of the shell & $0.024705 \mathrm{~m}$ \\
\hline Spacing between the baffles & $0.3 \mathrm{~m}$ \\
\hline Thickness of the tubular wall & $0.00165 \mathrm{~m}$ \\
\hline Number de baffles & 16 \\
\hline Number of passes on the shell & 1 \\
\hline Number of passes in the tubes & 4 \\
\hline Number of tubes & 998 \\
\hline Tubular step & $0.03175 \mathrm{~m}$ \\
\hline Outer radius of the tube & $0.0128525 \mathrm{~m}$ \\
\hline Inner radius of the tube & $0.0123525 \mathrm{~m}$ \\
\hline
\end{tabular}

\section{METHODOLOGY OF CALCULUS}

\section{Effectiveness Method}

In thermal analysis of heat exchangers there are two important procedures to be considered: the calculation of the thermal capacity and the dimensioning of the heat exchanger. According to Ozisik (2007), the assessment of the thermal capacity consists of the determination of the heat transfer rate, the outlet temperatures and the pressure drops; while the dimensioning consists of the determination of the sizes of shell and tubes needed to achieve the operational requirements.

When the inlet temperatures are known and the output temperatures can be specified or determined immediately by the expressions of the energy balance, the method of logarithmic mean temperature difference can be used. On the other side, when only the inlet temperatures and the flow rates of the fluids are known, the overall heat transfer coefficient has to be estimated. According to Holman (1983), the thermal analysis can be easily performed by the use of the effectiveness method. In Kreith (2003) the effectiveness is defined as follows:

$$
\varepsilon=\frac{Q}{Q_{\max }}
$$

where $Q$ is the actual heat transfer rate, and $Q_{\max }$ is the largest possible heat transfer rate.

Thus, the effectiveness $\varepsilon$ for heat exchangers can be determined by:

$$
\varepsilon=\frac{1-e^{-\beta A U}}{C_{\min } / C_{c}+C_{\min } / C_{h}}
$$

where $A$ is the heat transfer area, $U$ is the overall heat transfer coefficient, $C_{h}$ is the thermal capacity of the hot fluid, $C_{c}$ is the thermal capacity of the cold fluid, $C_{\min }$ is the minimum thermal capacity, $C_{\max }$ is the maximum thermal capacity, and $\beta$ is a parameter defined by:

$$
\beta=\frac{1}{C_{h}}+\frac{1}{C_{c}}
$$

For convenience, in practical applications a dimensionless parameter, the number of heat transfer units (NUT), is defined by:

$$
N=\frac{A U}{C_{\min }}
$$

Thus, according to Ozisik (2003), the equation (2) can be rewritten for heat exchangers in parallel streams as follows:

$$
\varepsilon=\frac{1-e^{-N C_{\min }\left(1 / C_{c}+1 / C_{h}\right)}}{C_{\min }\left(1 / C_{c}+1 / C_{h}\right)}
$$

Similar expressions can be find and the $\varepsilon-N U T$ relationships can be developed in heat exchangers having other arrangements, such as 
counter current, cross currents and multiple passes. Table 2 shows the relationships of the effectiveness for shell-and-tube heat exchangers with multiple passes.

Table 2. Relations of the effectiveness for heat exchangers shell and tube (Holman, 1983).

\begin{tabular}{c|c}
$\begin{array}{c}\text { Flow } \\
\text { configuration }\end{array}$ & Relationship \\
\hline $\begin{array}{c}\text { One pass in } \\
\text { the shell and } \\
2,4 \text { and } 6 \\
\text { passes in the } \\
\text { tubes }\end{array}$ \\
$\begin{array}{c}\text { All } \\
\text { exchangers, } \\
C=0\end{array}$ & $\varepsilon=2\left\{1+C+\left(1+C^{2}\right)^{1 / 2} \frac{1+e^{-N\left(1+C^{2}\right)^{1 / 2}}}{1-e^{-N\left(1+C^{2}\right)^{1 / 2}}}\right\}^{-1}$, \\
\hline
\end{tabular}

The $\varepsilon-N U T$ relationships can easily be used for solving thermal calculation and dimensioning problems. The heat transfer rate can be calculated as follows:

$$
Q=\varepsilon C_{\min }\left(T_{h, 1}-T_{c, 1}\right)
$$

where $T_{h, 1}$ is the inlet temperature of the hot fluid and $T_{c, 1}$ is the inlet temperature of the cold fluid.

Thus, the outlet temperatures are obtained from the following equations:

$$
T_{h, 2}=T_{h, 1}-\frac{Q}{C_{h}}
$$

and

$$
T_{c, 2}=T_{c, 1}+\frac{Q}{C_{c}}
$$

\section{Procedure for calculating outlet temperatures}

For calculating outlet temperatures, we establish an iterative procedure in which material properties (viscosity, thermal conductivity and density) are initially considered at inlet temperature for the fluids. Despite the overall heat transfer coefficient can vary due to changes in material properties and flow conditions (Incropera and Witt, 2008), in many applications such variation is not significant so that is reasonable to work with average values.

By applying the effectiveness method, we calculate the outlet temperatures. Then actual material properties are considered at average fluid temperatures of inlet and outlet sides. Based on the actual material properties, the calculation of outlet temperatures is performed again. This iterative procedure is carried out until convergence on the outlet temperatures is verified.

As the system of heat exchangers is constructed by heat exchangers in series, the outlet temperatures of previous heat exchanger are the inlet temperatures of posterior heat exchangers.

\section{RESULTS AND DISCUSSION}

\section{Validation of results for the existing configuration}

In Table 3 is presented outlet temperatures for the oil at the end of each pair of heat exchangers, for the existing configuration. Results from the effectiveness method and the data measured in situ can be compared in order to validate the method.

Table 3. Outlet temperatures for the oil.

\begin{tabular}{|c|c|c|}
\hline \multicolumn{3}{|c|}{ OUTLET TEMPERATURES $\left({ }^{\circ} \mathrm{C}\right)$} \\
\hline Exchangers & Calculated & Measured \\
\hline 1st pair & 84.036 & $77-84$ \\
\hline 2nd pair & 63.953 & $62-66$ \\
\hline 3rd pair & 50.683 & $55-59$ \\
\hline 4th pair & 41.932 & $37-41$ \\
\hline 5th pair & 36.243 & $36-40$ \\
\hline
\end{tabular}

The outlet temperature calculated by using the effectiveness method match the temperature range measured in situ. An exception for the third pair is observed (the error is about $8 \%$ ). The results for the existing configuration using the effectiveness method can be considered valid in relation to the data in situ. Thus, the method can be applied for evaluating the performance of alternative configurations of the system.

\section{Alternative configurations of the system}

For evaluating the performance of the system of heat exchangers, four alternative configurations will remain all geometric dimensions and components of each heat exchanger, just modifying operational conditions and flow looping.

In the first configuration, the water enters in each pair of heat exchangers in parallel. The water gets into both heat exchangers at $26^{\circ} \mathrm{C}$, as illustrated by the picture on the right side of the Fig. 2.

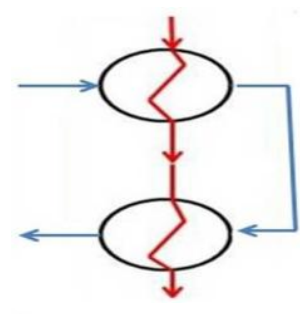

Existing Configuration

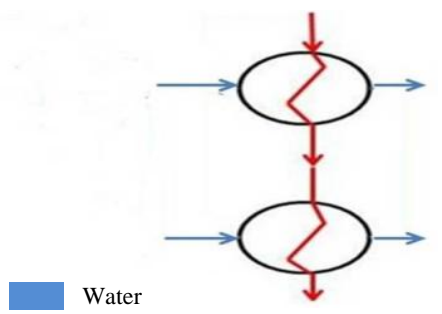

Proposed Configuration
Figure 2. Proposed water looping.

In the second configuration, the modification is made in mass flows. The water and oil mass flows 
are increased of $50 \%$ (the values are showed in the Table 4). All other parameters remain as the existing configuration. The mass flows affect strongly the thermal performance of the system.

Table 4. Increasing mass flows in the configuration.

\begin{tabular}{|l|c|c|}
\hline \multirow{2}{*}{} & \multicolumn{2}{|c|}{ Mass Flows (kg/s) } \\
\cline { 2 - 3 } & Existing System & $\mathbf{5 0 \%}$ increased \\
\hline Water in the shell & 83.34 & 125.01 \\
\hline Oil in the tubes & 47.41 & 70.71 \\
\hline
\end{tabular}

This configuration is proposed due to the mass flows directly affect the convective heat transfer coefficients in both shell and tubes, thereby influencing the efficiency of the system of heat exchangers. The $50 \%$ increase in the mass flows is proposed since small increases get a better performance of heat exchangers. Therefore, we expect a significant improvement in the performance with the increase of mass flows.

The third configuration is a combination of the previous two configurations. That is, water at $26^{\circ} \mathrm{C}$ enters in each pair of heat exchangers in parallel, as illustrated on the right of the Fig. 2, and the mass flows of the fluids are increased of $50 \%$, as shown in Table 4.

The fourth configuration consists of changing the direction of the water flow. On the contrary of the existing configuration, the water first gets into the even heat exchangers, and next gets into the odd heat exchangers, as illustrated in the Fig. 3. This modification permits that average temperatures of the water approaches to the average temperatures of the oil, improving the heat transfer in counter flow heat exchangers.

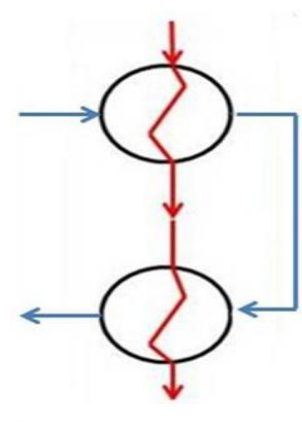

Existing Configuration
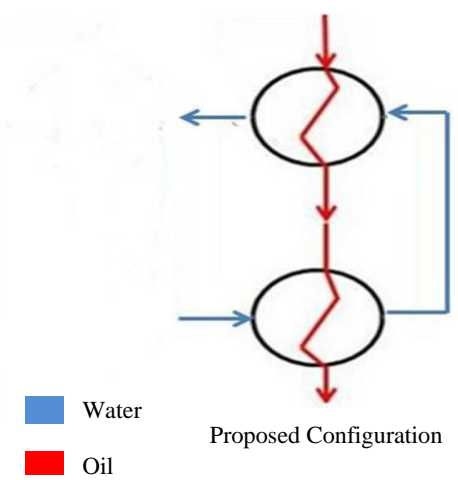

Proposed Configuration
Figure 3. Proposed water direction.

\section{Installation costs for alternative configurations}

In this section, we present the installation costs for the alternative configurations based on current values referenced to the market. These values may be subjected to changes from time to time.

For implementing the first configuration are needed structural modifications, basically concerning the tubes. The second configuration requires the replacement of water and oil pumps, what means higher material costs. The third configuration brings together the previous costs. The fourth configuration is the simple and cheapest one. The installation costs for the alternative configurations can be seen in the Table 5.

Table 5. The installation costs for the configurations.

\begin{tabular}{|c|c|c|c|}
\hline \multirow{2}{*}{} & \multicolumn{2}{|c|}{ Cost (R\$) } & \multirow{2}{*}{ Total (R\$) } \\
\cline { 2 - 3 } & Hand labor & Material & \\
\hline 1st alternative & $47,051.20$ & $36,029.55$ & $83,080.75$ \\
\hline 2sd alternative & $43,820.48$ & $235,000.00$ & $278,820.48$ \\
\hline 3rd alternative & $90,870.68$ & $271,029.55$ & $361,900.23$ \\
\hline 4th alternative & $11,762.80$ & $12,009.85$ & $23,772.65$ \\
\hline
\end{tabular}

\section{Performance of the configurations}

A curve of outlet temperatures of the oil is presented in the Fig. 4. The goal of the system of heat exchangers is to achieve outlet temperatures for the oil less than $36^{\circ} \mathrm{C}$, according to the operational condition of the chemical plant. The first and second configurations have the outlet temperatures less than $36^{\circ} \mathrm{C}$ at end of the 4 th pair of heat exchangers, which means that the last pair can be taken away or operated in stand-by. This represents a great economy in terms of maintenance cost. Currently, maintenance in the existing configuration is carried out at six-month time interval, for each pair of heat exchangers.

Despite of all alternative configurations have succeeded in general, another parameters must be investigated. For example, the inlay process cause trapping in tubes, and consequently increases the maintenance costs. So the system must be prevented against this process. According to Fiorentin (2004), the inlay process can arise from chemical reactions. An increase in temperatures contributes to the increase in reaction rate, and in the inlay process. In the first configuration, the water enters in each heat exchanger in parallel providing low temperatures in tubes, and decreasing the inlay process. In the fourth configuration, the inlay process decreases since the lowest temperatures are observed in the counter crossing flow. In the second and third configurations, the increasing mass flows provide an increase in flow velocities, and consequently a decrease the inlay process.

\section{CONCLUSIONS}

All the alternative configurations have presented improvements in thermal performance of the system of heat exchangers, reducing the outlet temperatures for the oil. However, the second and third configurations require high implementing costs. The fourth configuration has the lowest implementing costs, but also the lowest improvement in thermal performance. 


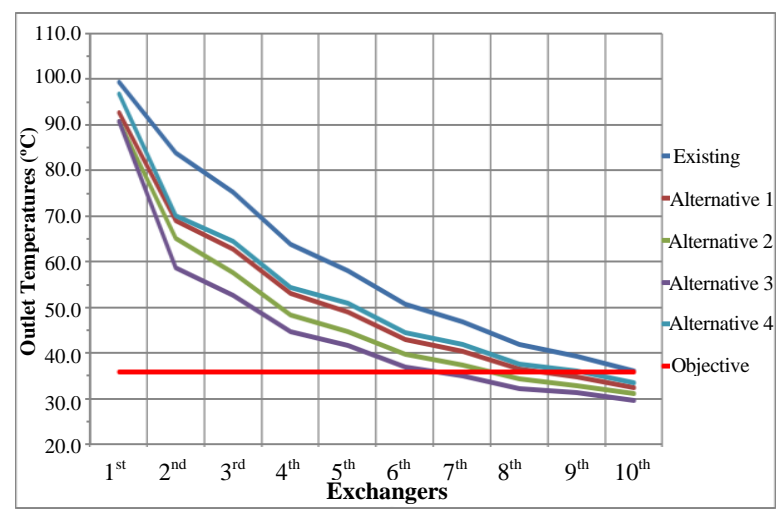

Figure 4. Outlet temperatures of the oil in each heat exchanger.

The first configuration is the best one, since it has showed low installation cost combining with reasonable thermal performance. The implementation of this alternative configuration could provide a decrease in the inlay process, and allows the system to be operated with one pair of heat exchangers in stand-by, saving the maintenance costs.

According to Madi (2005), supervising the performance of heat exchangers is a good way of quantifying the costs related to inlay process and identifies the appropriate period of cleaning. Follow that, the first configuration can provide a great advantage regarding to the maintenance, without compromising production.

\section{REFERENCES}

ASME, 2007, Rules for Construction of Pressure Vessels, section VIII, Div. 1.

Fiorentin, L. D., 2004, Estudos em Modelos Matemáticos para Previsão de Incrustação por Coque em Tubulações, Master Thesis, Centro Federal de Educação Tecnológica do Paraná, Curitiba, PR. (in Portuguese)

Holman, J. P., 1983, Transferência de Calor, McGraw-Hill. (in Portuguese)

Kreith, F., and Bohn, M. S., 2003, Princípios de Transferência de Calor, Pioneira Thomson Learning. (in Portuguese)

Incropera, F. P., and Witt, D. P., 2008, Fundamentos de Transferência de Calor e de Massa, Livros Técnicos e Científicos Editora S.A. (in Portuguese)

Madi, M., 2005, Otimização do Período de Limpeza de Trocadores de Calor Utilizados no Refino de Petróleo, Master Thesis, Centro Federal de Educação Tecnológica do Paraná, Curitiba, PR. (in Portuguese)

Oliveira, G. A., 2010, Dimensionamento de um Trocador de Calor Tipo Casco e Tubos, Undergraduate Thesis, Universidade Federal de Uberlândia, Uberlândia, MG. (in Portuguese)

Ozisik, M. N., 2007, Transferência de Calor: um Texto Básico, Editora Guanabara. (in Portuguese)
Tonin, P. C., 2003, Metodologia para Monitoramento do Desempenho Térmico de Redes de Trocadores de Calor, Master Thesis, Centro Federal de Educação Tecnológica do Paraná, Curitiba, PR. (in Portuguese) 